\title{
Identification of Bioactive Phytochemicals from Six Forest Plants: Insights into the Mechanistic Inhibition of Rumen Protozoa, Ammoniagenesis, and A- Glucosidase
}

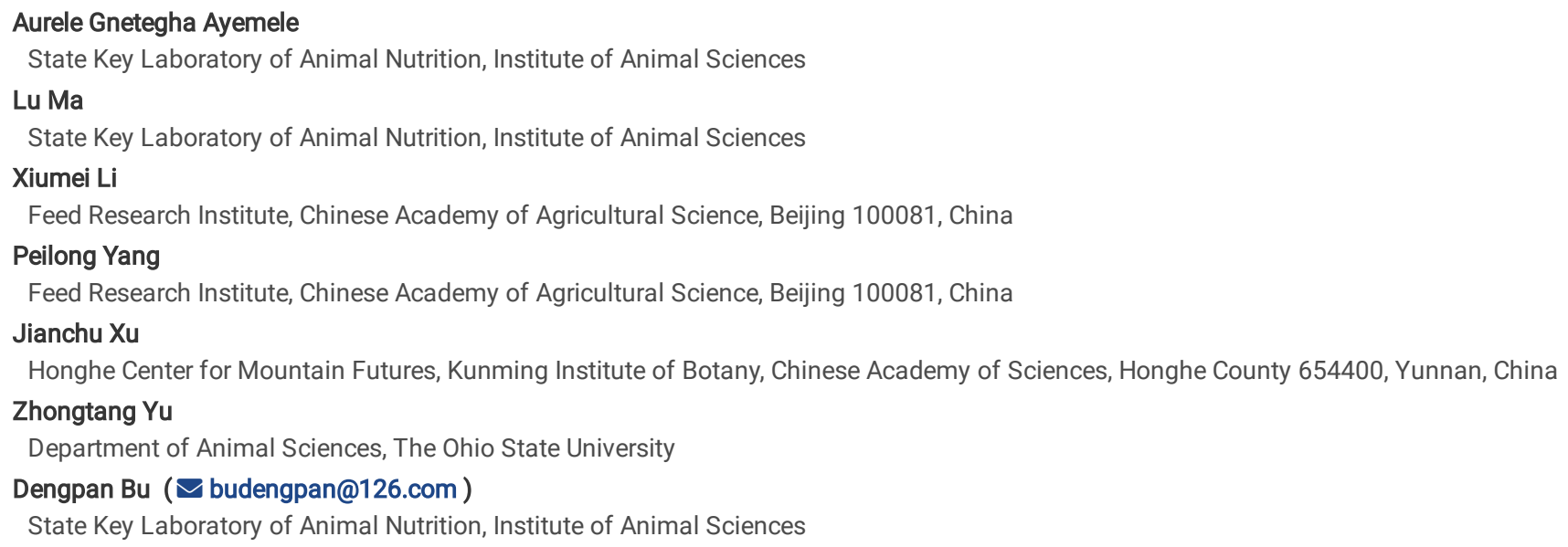




\section{Abstract}

Rumen protozoa have a little contribution to the feed digestibility but Entodinium, the most predominant genus, is unfortunately culprit of the nitrogen utilization inefficiency. To bridge the gap, antibiotics have been used to inhibit the rumen protozoa but unfortunately, due to the health concern, this could not be really applied at the farm level, especially in the organic farms where the use of natural plants is an utmost priority. Therefore, our study aimed at investigating the nutritional and functional properties of six forest plants for their potential as feed additives in animal husbandry. The plants were analyzed for major phytochemicals using reversed phase-HPLC analysis and then evaluated for their in-vitro suppressing effect on rumen protozoa, ammoniagenesis, and microbial a-glucosidase activity. For each plant, four doses $(0,0.7,0.9$, and $1.1 \mathrm{mg} / \mathrm{mL}$ culture fluid) displayed in a complete randomized design were used. Quercetin, anthraquinone, 3-hydroxybenzoic acid, astragaloside, and myricetin were found to different extent $(P \leq 0.05)$ in the plant leaves. All the tested plants reduced total rumen protozoa counts but $C$. gigantea and $B$. rapa had the most inhibitory effect $(P \leq 0.05)$, inhibiting the rumen protozoa by 45.6 and $65.7 \%$, respectively, at the dose of $1.1 \mathrm{mg} / \mathrm{mL}$. Moreover, the scanning electron microscopy revealed the mechanistic disruption of the extracellular membrane of the protozoa, indicating their metabolic death pathway. Only $C$. gigantea inhibited the rumen protozoa in a proportion that also led to the reduction of the wasteful ammonia production $(P \leq 0.05)$. Besides, $A$. digitata and $F$. macrophylla have the higher inhibition rate $(70 \%)$ of the microbial a-glucosidase activity at $100 \mu \mathrm{g} / \mathrm{mL}$ of crude extract. Overall, the plants showed promising results as functional feed additives although future research on bio-guided fractionation is needed to accurately identify the pure anti-protozoal bioactive compound(s).

\section{Introduction}

Ruminants can convert fibrous plant materials into meat and milk products for human consumption. However, feed efficiency remains a big challenge, especially nitrogen utilization efficiency (NUE), which is no more than $30 \%$ as most of the dietary nitrogen is excreted as urea and ammonia ${ }^{1}$, negatively influencing the environment and increasing feeding cost. In particular, rumen protozoa engulf the cells of rumen microbes (primarily bacteria), which are the main source of metabolized protein for the host animals synthesized from the diet, and degrade the microbial protein into oligopeptides and free amino acids, both of which are converted to ammonia, lowering NUE ${ }^{2}$. To bridge the gap, antimicrobials have been used to improve feed utilization efficiency including NUE, but unfortunately, some side effects on both the animal products and human consumers have been reported ${ }^{3}$. This situation led to the ban of antimicrobials as feed additives and calls for a renewed interest in using plants as a source of natural alternatives, especially in organic animal husbandry. A recent study ${ }^{4}$ demonstrated that the leaves of Calotropis gigantea, which contains phytochemical groups, such as phenolics, flavonoids, and alkaloids, could effectively inhibit rumen protozoa (by nearly $60 \%$ ) and thereby decreasing the wasteful ammoniagenesis in vitro. More importantly, $C$. gigantea did not adversely affect fermentation characteristics. By far, no study has described the mechanism of inhibition of rumen protozoa by bioactive phytochemicals. Using scanning and transmission electron microscopy, Park et al. ${ }^{5}$ showed that antibiotics and inhibitors of protozoal digestive enzymes could destruct the cellular structure of Entodinium and other rumen protozoa both extracellularly and intracellularly.

High-producing ruminants are generally fed with diets rich in rapidly fermentable carbohydrates leading to an upsurge of volatile fatty acids (VFA) and consequently a dramatic decrease of the rumen $\mathrm{pH}$, which in turn causes ruminal acidosis and associated metabolic disorders and depressed milk yields ${ }^{6}$. The rapid degradation of carbohydrates or polysaccharides is due to the enzymatic activity of microbial amylase and glucosidase, which needs to be regulated to mitigate rumen acidosis. To that end, acarbose has been used as a synthetic inhibitor of a-glucosidase to raise the rumen $\mathrm{pH}$, but unfortunately, like other synthetic drugs, acarbose was associated with serious side complications ${ }^{7}$. In addition, the use of acarbose to alleviate ruminal acidosis also led to the increase of ammonia nitrogen $\left(\mathrm{NH}_{3}-\mathrm{N}\right)$ concentration ${ }^{8}$, which decreases NUE. Moreover, as a drug treat diabetes, acarbose is too expensive to be fed to ruminants. It becomes urgent to explore natural alternatives from plants as alternatives to inhibit microbial a-amylase and a-glucosidase enzymatic activity and lower the risk of rumen acidosis.

Some forest plants, such as the fruit pulp of Adansonia digitata (baobab), have been shown to inhibit a-glucosidase activity ${ }^{9}$. Those plants contain various bioactive and antimicrobial phytochemicals, and yet most of them have not been explored for their potential as feed or feed additives for ruminants. In a

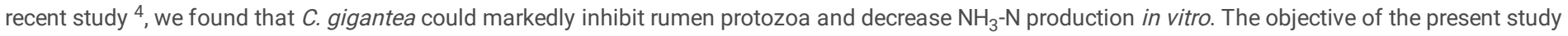
was to analyze another six plants in comparison with $C$. gigantea for their potential to inhibit rumen protozoa, decrease ammonia production, and regulate the activity of a-glycosidase using in vitro rumen cultures. We hypothesized that some of those plants, such as Flemingia macrophylla (waras tree), Kalimeris indica (Indian aster), Brassica rapa subsp. chinensis (bok choy), Portulaca oleracea (common purslane), and C. gigantea, none of which had not yet been tested in animal nutrition, could be used as a source of protein and fiber in typical diets of ruminants and also at the same time, as inhibitors of detrimental protozoa, ammoniagenesis, and starch digestion. This study aimed to test the above hypothesis by exploring the above forest plants through evaluating their inhibitory effect on total rumen protozoa and a-glucosidase and identifying their major phytochemicals for the mechanistic understanding of their effects.

\section{Results}

Proximate composition and total polyphenols. Crude protein, ether extract, fiber, and ash were the main nutrients detected on a dry matter (DM) basis (Table 1). $K$. indica recorded the highest protein content, while F. macrophylla roots the lowest. Regarding the NDF/ADF content, F. macrophylla and C. gigantea had a higher value than the other plants. The ether extract yield was quite low for all the tested plants, and $C$. gigantea had the highest value. Ash content was found higher in P. oleracea and $C$. gigantea than in the other plants. The roots of $F$. macrophylla had the lowest ash content.

The plants had different yields of extracts and different content of phenolics, flavonoids, and alkaloids. $B$. rapa subsp. chinensis (the tubers) had the highest crude extract yield, while F. macrophylla and P. oleracea recorded the lowest. Phenolic content was found the highest in $F$. macrophylla, followed by $A$. digitata and $C$. gigantea. B. rapa subsp. chinensis (tubers) and $P$. oleracea had the lowest phenolic content. The highest total flavonoid content was found in $C$. 
gigantea and the lowest in B. rapa subsp. chinensis (tubers). Except for F. macrophylla that had the highest total alkaloid content, the other plants recorded the lowest proportion of alkaloids compared to the phenolic and flavonoid content.

Quantification of some individual phytochemical compounds. Among the studied plants, $A$. digitata appeared to rich in 3-hydroxybenzoic acid, astragaloside, and myricetin as it had the highest content of those individual compounds, while $K$. indica was rich in 3-hydroxybenzoic acid, $C$. gigantea rich in quercetin, $F$. macrophylla, P. oleracea, and B. rapa subsp. chinensis rich in astragaloside (Table 2). F. macrophylla roots also contain a high level of 3-hydroxybenzoic acid.

Effects on rumen protozoal counts and ammoniagenesis of in vitro culture. All the tested plants inhibit the total protozoa counts though to a different extent (Fig. 1). At the tested maximum dose of $1.1 \mathrm{mg} / \mathrm{mL}, B$. rapa subsp. chinensis had a higher inhibitory effect with a $65.7 \%$ reduction than $A$. digitata with a $47.6 \%$ reduction and finally $C$. gigantea with a reduction by $45.6 \%(P<0.05)$. K. indica, F. macrophylla, and $P$. oleracea suppressed the protozoal count by $24 \%$, $9.5 \%$, and $8 \%$, respectively. Only $C$. gigantea and $A$. digitata decreased protozoa at the lowest dose tested $(0.7 \mathrm{mg} / \mathrm{mL})(P<0.05)$. B. rapa subsp. chinensis, $K$. indica, P. oleracea, and $A$. digitata did not affect $\mathrm{NH}_{3}-\mathrm{N}$ production $(P>0.05)$ (Table 3) but $C$. gigantea reduced the production of $\mathrm{NH}_{3}-\mathrm{N}$, whereas $F$. macrophylla (leaves and roots) increased the ammoniagenesis $(P<0.05)$.

Disruption of the cells surface of Entodinium by the tested plants. The extracellular surface (pellicles) of Entodinium cells collapsed and wilted by the tested plants (Fig. 2). The normal longitudinal striations present on the cell surface disappeared after the exposure to B. rapa subsp. chinensis, $K$. indica, and $A$. digitata, but the treatments with C. gigantea, F. macrophylla or $P$. oleracea or the control did not destruct the striations.

Antidiabetic potential of the plants leaves. All the tested plants inhibited a-glucosidase activity, but different plants exhibited different effects, with $B$. rapa chinensis maintaining similar inhibition as its dose increased, while the other plants lost inhibition potency with the increased doses (Fig. 3). More intriguingly, C. gigantea, F. macrophylla, and $K$. indica stimulated the activity of a-glucosidase at their higher doses. Only F. macrophylla and A. digitata inhibited half of the a-glucosidase concentration, at the lowest amount of required extract (IC50 value). As expected, acarbose inhibited a-glucosidase in a dose-dependent manner. It remains to be determined if a-glucosidase is stimulated by other plant compounds when they reach their threshold concentration when sufficient plant leave extracts are added.

\section{Discussion}

Many synthetic products are still used either as inhibitors of certain gut microbes and their enzymes or as growth promoters at different levels to control or regulate some physiological functions of food-producing animals. Unfortunately, those synthetic products are nowadays recognized to have adverse effects associated with global public health concerns. Therefore, many of those chemicals are being banned, and natural alternatives are highly sought after. This study investigated for the first time some forest plants harvested in China, which have not yet been explored as modulators of ruminant nutrition. The study provided information on the basic nutritional composition, the major bioactive phytochemicals, and the inhibitory effect on total rumen protozoa, ammoniagenesis, and a-glucosidase activity of the selected plants.

The content of protein, NDF, ADF, and ash of $K$. indica, P. oleracea, $B$. rapa subsp. chinensis (tubers) were reported for the first time in this study. Abiona et al. ${ }^{10}$ found a protein content of $13.6 \%$ in A. digitata leaves collected in the state of Oyo in Nigeria. F. macrophylla foliage collected from the southern part of Vietnam contained $16 \%$ proteins, $64.7 \%$ NDF, and $53.4 \%$ ADF ${ }^{11}$. A. digitata, K. indica, C. gigantea, and P. oleracea had a protein content greater than $16 \%$, and thus they could be used as a potential source of protein in the ration fed to dairy cows. Moreover, the fat-rich plants are involved in the insulation of organs for the maintenance of body temperature and cell function and they could be explored as sources of omega- 3 and omega- 6 fatty acids, which can promote health in both animals and humans, digestion, absorption, and transport of vitamins ${ }^{12}$. Flavonoids are a group of phenolic compounds widespread in plants and highly regarded for their health-promoting and disease-preventing potentials, anti-virus and anti-protozoal activities ${ }^{13,14}$. Future studies are needed to evaluate if they affect palatability, feed intake, or feed digestion in animal husbandry.

To the best of our knowledge, the tested plants have not yet so far been analyzed for the tested individual phytochemical compounds. Some studies just reported the qualitative screening of phytochemicals including flavonols, terpenes, and cardenolide glycosides in $C$. gigantea ${ }^{13,15,16}$. A recent study also detected the presence of $p$-hydroxybenzoic acid, 4-O- $\beta$-d-galactopyranosyl-d-fructose, myrciacitrin IV, quinic acid, and derivatives of astragaloside/quinic acid in C. procera, a plant species of the same genus as Calotropis gigantea ${ }^{17}$. A. digitata contained quercetin 3-O-glucoside ${ }^{18}$, iridoid, phenylethanoid, and hydrocinnamic acid glycosides ${ }^{19}$.The bioactive compounds found in the tested plants have demonstrated functional values such as antioxidant, antiinflammatory, antidiabetic ${ }^{17}$ and antimicrobial activities especially against pathogenic Gram-negative bacteria ${ }^{20}$. Moreover, the antimicrobials content found in the plants can be considered as a potential source of novel antimicrobial function required to manipulate the rumen microbiota, and thereby optimizing feed efficiency.

The effect of $C$. gigantea on rumen protozoa has been recently evaluated at the genus level, and about half of the Entodinium population, which dominates the rumen protozoal community, was inhibited ${ }^{4}$. At the same time, the other genera of rumen protozoa, such as Isotricha, Epidinium, and Dasytricha, were maintained, and thus their contribution to fiber digestion should not be compromised. Moreover, holotrich protozoa (Isotricha and Dasytricha), which have a lower predatory bacterial activity compared to the entodiniomorphids ${ }^{21}$, will ultimately have a lower impact on $\mathrm{NH}_{3}-\mathrm{N}$ concentration ${ }^{22}$ and duodenal microbial protein flow ${ }^{23}$. When the protozoal population is reduced, the ciliate-associated prokaryotic cells (ectosymbionts) such as members of Acidobacteria and Actinobacteria ${ }^{24}$ were also reduced, and this helps understand that the considerable limitation of the total removal of the whole protozoa population (defaunation) might lead to the tremendous decrease of the desired Actinobacteria and VFA concentration, especially butyrate ${ }^{22}$, which had been found reduced by $24 \%$ after 5 h of in vivo fermentation in defaunation trials ${ }^{25}$. Indeed, Ampapon et al. ${ }^{26}$ reported that supplementation of phytonutrients decreased the total protozoal counts by around $25 \%$, increased amylolytic, proteolytic, and cellulolytic bacteria, enhanced fiber digestibility, and reduced

Page $3 / 11$ 
methane production. Similarly, Prevotella species that constitute one of the preferred preys of protozoa ${ }^{24}$ were more abundant in the rumen of high-milk and high-proteins milk producing dairy cows ${ }^{27}$ elucidating why protozoa contribute to lower down NUE ${ }^{4}$. Meanwhile, except for $A$. digitata, which has been used for its multiple health benefits, the other tested plants still await further clinical confirmation or toxicological studies before applications in animal nutrition.

Studies on defaunated-refaunated animals using dietary chemical agents, rumen washing, animal isolation, and immunological approaches have been previously carried out to suppress the growth of rumen protozoa ${ }^{28,29}$. However, none of those approaches is really practical at the farm level ${ }^{30}$. Chemicals like imidazole at $100 \mathrm{mmol} / \mathrm{L}$ inhibited rumen ciliate protozoa with the maintenance of $\mathrm{NH}_{3}-\mathrm{N}$ production after $24 \mathrm{~h}$ of in vitro incubation of protozoal cultures 31 , which is consistent with our results using plants, but $C$. gigantea decreased the $\mathrm{NH}_{3}-\mathrm{N}$ concentration while $F$. macrophylla rather increased it. Besides, myricetin and quercetin were found in the tested plants, and these two compounds were shown to inhibit total rumen protozoa ${ }^{32}$. Future research using bioguided fractionation can help to confirm if these two compounds lonely or in association, are responsible for the observed inhibition of rumen protozoa by the plants.

The disruption of cell surface structure of protozoa has been reported by Zeitz et al. ${ }^{33}$ as one of the signs of the dying rumen ciliate protozoa. Such a disruption of the cell surface structure leads to the loosened appearance of the filamentous glycocalyx, the non differentiation of chromatin and granular nucleoli, the accumulation of glycogen granules that obstructs the normal cell physical processes and ATP utilization ${ }^{5,34}$. Furthermore, the disruption of the protozoal cell surface will also quarrel the ectosymbiosis with the associated microbiota ${ }^{35}$, and the transport of soluble nutrients in unicellular parasitic protozoa will subsequently be compromised ${ }^{36}$. The hydrogen transporter will also be compromised which might contribute to a reduction of $\mathrm{CH}_{4}$ release.

One of the well recognized and effective approaches for keeping the level of glucose from rapid rising in the serum is the inhibition of a-glucosidase with a specific inhibitor, such as acarbose ${ }^{37}$. Although this does not apply to ruminant animals because they had little dietary sugars reaching the small intestines, digestion of starch after the feeding of high-concentrate diets can lead to rapid release of glucose, which is readily fermented to VFA, resulting in rumen acidosis. In lactating cows fed a high carbohydrate ration, the supplementation of acarbose prevented ruminal pH from lowering to the critical level of rumen acidosis ${ }^{38}$. Therefore, the tested plants, all of which can grow in dry or arid lands, may be used as alternatives of acarbose to lower the risk of or prevent rumen acidosis. An anti-glucosidase guided fractionation assays of the plants are needed to identify the component(s) responsible for the a-glucosidase inhibition. Meanwhile, some components have been found in the tested plants, and previous studies have ascribed the inhibitory effect of a-glucosidase activity to those components. Indeed, Mukhopadhyay and Prajapati ${ }^{39}$ reported how the quercetin flavonoid displayed inhibition of a-glucosidase activity, a remarkable hypoglycemic effect that improved and stabilized the secretion and regeneration of insulin in human pancreatic islets with no significant health hazards. Also, the administration of myricetin in diabetic rats resulted in a $50 \%$ decrease in hyperglycemia and an augmentation in hepatic glycogen and glucose-6-phosphate content ${ }^{40}$. This clearly demonstrated that the myricetin-rich plants tested in the present study could also have some anti-diabetic properties and deserve more attention as sources of functional feed and food.

\section{Materials And Methods}

All experimental work and field studies on plants, including the collection of plant in this study, had complied with relevant institutional, national, and international guidelines and legislation.

Plants collection and proximate analysis. Forest plants were collected in Honghe, located in the southwest of Yunnan province, China. The plants were selected based on their ethnobotanical values for traditional Chinese medicine. They were taxonomically identified and confirmed by Prof. Liu Yi, a botanist of the Herbarium Botanical Institute of Kunming, Chinese Academy of Sciences where their voucher numbers are recorded. They included $A$. digitata (FJSI011773), B. rapa subsp. chinensis (BNU0018604), C. gigantea (KUN0307207), F. macrophylla (KUN0616353), K. indica (KUN0983258), and P. oleracea (KUN1063740). After collection, the plant parts were used following the standard operating procedures established by the Good Agriculture Practices ${ }^{41}$. Indeed, the leaves were separated from the stems, sun-dried, and grounded to pass through a $2 \mathrm{~mm}$ mesh for nutritional analysis and a $0.3 \mathrm{~mm}$ mesh to be used as the feed of the protozoal cultures and subjected to crude extraction and phytochemical analysis (for $F$. macrophylla, both leaves and roots, for $B$. rapa chinensis, only its tuber). Finally, the ground plant samples were stored in glass bottles and kept at room temperature until further analysis. Nutritional analysis was done using standard methods ${ }^{42}$ for dry matter (DM), ash, crude protein, ether extract. Neutral detergent fiber (NDF) and acid detergent fiber (ADF) were determined by the methods outlined by Goering and Van Soest ${ }^{43}$.

Reagents and chemical analysis of plants.

Chemicals and reagents used. Gallic acid (CAS No.: 5995-86-8, $\geq 98 \%$ purity), rutin (CAS No.: 153-18-4, $\geq 98 \%$ ), aconitine (CAS No.: 302-27-2, $\geq 98 \%$ ), 3hydroxybenzoic acid (CAS No.: 99-06-9, $\geq 99 \%$ ), quercetin (CAS No.: 117-39-5, $\geq 98 \%$ ), acetonitrile (CAS No.: 75-05-8, $\geq 98 \%$ ), methanol (CAS No.: 67-56-1, $\geq$ 98\%), and ethanol (CAS No.: 64-17-5, $\geq 98 \%$ ) were bought from Sigma-Aldrich (St. Louis MO, USA). Anthraquinone (CAS No.: 84-65-1), astragaloside (CAS No.: 17429-69-5), myricetin (CAS No.: 529-44-2, $\geq 98 \%$ ) were bought from Yuanye Biotechnology Ltd. (Shanghai, China).

Plant sample preparation and extraction. The finely ground plant samples ( $0.3 \mathrm{~mm}$ particles) were individually subjected to chemical extraction according to the procedures described by Ayemele et al. ${ }^{4}$. Briefly, $15 \mathrm{~g}$ of each ground plant sample was combined with $450 \mathrm{~mL}$ of $80 \%$ ethanol. The mixture was subjected to ultrasonication using a Soniprep 150 Ultrasonicator (Hongxianglong Biotechnology Co., Ltd. Beijing, China) at $55^{\circ} \mathrm{C}$ for $45 \mathrm{~min}$ at $90 \%$ of its maximum power level. The sonicated samples were then centrifuged $(10,000 \mathrm{rpm}$ for $10 \mathrm{~min})$, and the supernatants were collected and evaporated at $55^{\circ} \mathrm{C}$ in a rotary evaporator set at $85 \mathrm{rpm}$. Around $20 \mathrm{~mL}$ of the crude extract from each sample was freeze-dried at $-70^{\circ} \mathrm{C}$ for $72 \mathrm{~h}$, and the final extract was weighted. 
Quantification of total phenolic, flavonoid, and alkaloid of the crude extract. The crude extract samples were analyzed for total phenolic compounds (TPC), total flavonoid compounds (TFC), and total alkaloid content (TAC) as previously described $4,44,45$. The content (per gram of plant leaves) of TPC, TFC, and TAC were respectively estimated as $\mu \mathrm{g}$ of gallic acid equivalent ( $\mu \mathrm{g} \mathrm{GAE} / \mathrm{g}), \mu \mathrm{g}$ of rutin equivalent ( $\mu \mathrm{g} \mathrm{RE} / \mathrm{g})$, and $\mu \mathrm{g}$ of aconitine equivalent ( $\mu \mathrm{g} \mathrm{AE} / \mathrm{g}$ ).

Reversed-phase HPLC for quantification of individual plant metabolites. Major secondary metabolites in the crude extract samples were analyzed using reversed-phase HPLC (RP-HPLC) as described by Ayemele et al. ${ }^{4}$. Briefly, the analysis consisted of separation, detection, and quantification of the compounds using the Agilent ZORBAX EclipsPlus C-18 reversed-phase column, a diode array detector, and an autosampler (Agilent Technologies, 1290 Infinity II, Palo Alto, CA, USA). Spectral data were recorded from 200 to $800 \mathrm{~nm}$, and the chromatograms of the compounds of interest were monitored at $326 \mathrm{~nm}$. The chromatographic peaks of the plant compounds were confirmed by comparing the retention time with those of the following reference standards: 3 hydroxybenzoic acid, myricetin, astragaloside, quercetin, and anthraquinone. The content of individual compounds was expressed as $\mu \mathrm{g} / \mathrm{g}$ of plant samples (DM).

In vitro culture of rumen protozoa and evaluation of plant effects

Collection of rumen fluid and preparation of concentrated rumen protozoa. Animals were handled and cared for following the guidelines approved by the Animal Care Advisory Committee of the Chinese Academy of Agricultural Sciences that approved the rumen fluid collection method. Rumen fluid was collected from three cannulated dairy cows and transported to the laboratory within 1.5 hours, following the procedures as previously reported ${ }^{4}$. Immediately after the rumen fluid was brought to the laboratory, the protozoa cells were sedimented under a continuous $\mathrm{O}_{2}$-free $\mathrm{CO}_{2}$ flux, and the top portion of the rumen fluid was removed. The remaining rumen fluid with concentrated protozoal cells was used as the inoculum in the in vitro culture experiments and evaluation of the plants.

In vitro culture of rumen protozoa with plant supplementation. The in-vitro culture technique of rumen protozoa was done as reported by Ayemele et al. ${ }^{4}$ Briefly, $8 \mathrm{~mL}$ of medium ${ }^{43}$ was dispensed into individual glass culture tubes containing $100 \mathrm{mg}$ of the same TMR fed to the lactating cows that donated the rumen fluid. Each of the ground plant samples was added to the glass culture tubes at four doses $(0,0.7,0.9, \mathrm{and} 1.1 \mathrm{mg} / \mathrm{mL}$ culture fluid) with each dose having three replicates $(n=3)$. Finally, $2 \mathrm{~mL}$ of the concentrated rumen protozoa were added under a continuous flux of $\mathrm{O}_{2}-$ free $\mathrm{CO}_{2}$. The tubes were incubated at $39^{\circ} \mathrm{C}$ for $24 \mathrm{~h}$. Each in vitro culture was sampled for protozoa counting and detection of $\mathrm{NH}_{3}-\mathrm{N}$ concentration.

Microscopic counting of rumen protozoal cells. The protozoal cells were morphologically identified and counted microscopically using the procedures previously described ${ }^{4,5}$. Briefly, $0.3 \mathrm{~mL}$ of each in vitro culture sample was combined with $0.3 \mathrm{~mL}$ of $18.5 \%$ formalin to fix the protozoal cells. Then, $30 \mu \mathrm{L}$ of a brilliant green dye solution was added to stain the protozoal cells. Finally, $1.4 \mathrm{~mL}$ of $30 \%$ glycerol was added to each tube and mixed. The cells were counted using a Sedgewick-Rafter counting chamber (Thomas Scientific, Swedesboro, NJ) under a light microscope at 10X magnification.

Scanning electron microscopy for protozoal cells surface. The samples of cultured rumen protozoa cells were prepared for scanning electron microscopy following the procedures previously described et al. ${ }^{4}$. Briefly, protozoal cells were pelleted by centrifugation at $500 \times \mathrm{g}$ for $5 \mathrm{~min}$ from $1 \mathrm{~mL}$ of each in vitro culture. Then, the cells were fixed with $3 \%$ glutaraldehyde and subsequently rinsed twice with a potassium phosphate buffer ( $0.1 \mathrm{M}, \mathrm{pH} 7.2)$. A sequential washing of protozoal cells with $30,50,70,90$, and $100 \%$ ethanol helped to dehydrate the cells, followed by washing in acetone and then

hexamethyldisilazane. The cells were then spatter-coated with platinum and viewed on a Hitachi S-4700 (Hitachi America, Ltd.) after five hours of drying with a flux of $\mathrm{CO}_{2}$.

Detection of ammonia nitrogen concentration. $\mathrm{NH}_{3}-\mathrm{N}$ concentrations of the culture fluid were determined using the colorimetric method described by Chaney and Marbach ${ }^{46}$. Briefly, $500 \mu \mathrm{L}$ and $400 \mu \mathrm{L}$ of the solutions A and B, respectively, were successively added and mixed with $8 \mu \mathrm{L}$ of each sample, and then incubated for $30 \mathrm{~min}$ at $37^{\circ} \mathrm{C}$. In a 96-well microplate, $200 \mu \mathrm{L}$ was dispensed to each well and optical absorbance was determined at $550 \mathrm{~nm}$ wavelength using a spectrophotometer (Thermo Fisher Scientific, Waltham, USA). A serial dilution of ammonia solution $(1,2,4,8,16$, and $32 \mathrm{mg} / \mathrm{dL})$ served as the external standard.

a-glucosidase inhibitory assay. The a-glucosidase inhibition assay was performed according to the procedures of Obaroakpo et al. ${ }^{37}$ and Rengasamy et al. ${ }^{47}$ with minor modification. Briefly, a-glucosidase obtained from Saccharomyces cerevisiae was dissolved in $0.1 \mathrm{M}$ potassium phosphate buffer (PBS, pH 6.8) and used as the enzyme stock solution $(0.1 \mathrm{Unit} / \mathrm{mL})$. The substrate for the enzyme activity assay was $p$-nitrophenyl-a-D-glucopyranoside (pNPG) dissolved in the same PBS buffer (stock concentration of pNPG: $0.375 \mathrm{mM}$ ). Inhibition to the yeast a-glucosidase was determined at five concentrations ranging from 100 to $500 \mu \mathrm{g} / \mathrm{mL}$ with an increment of $100 \mu \mathrm{g} / \mathrm{mL}$ of each plant extract in PBS, using 96-wells microplates. Acarbose, which is an inhibitor of a-glucosidase, served as the positive control at the above concentrations. Each a-glucosidase assay reaction contained $20 \mu \mathrm{L}$ of each plant extract solution, $20 \mu \mathrm{L}$ of aglucosidase enzyme solution, and $40 \mu \mathrm{L}$ of pNPG. The mixture was incubated at $37^{\circ} \mathrm{C}$ for $40 \mathrm{~min}$, and then $80 \mu \mathrm{L}$ of $0.2 \mathrm{M}$ sodium carbonate in PBS was added to terminate the reaction. Optical absorbance was read using a spectrophotometer (Thermo Fisher Scientific, Waltham, USA) at $405 \mathrm{~nm}$. One negative control was included in parallel that contained no plant extract or acarbose. Each assay reaction had three replicates. The inhibition (\%) was calculated using the following equation:

\section{Inhibition $=\left(A_{\text {control }}-A_{\text {sample }}\right) / A_{\text {control }} \times 100$}

where $\mathrm{A}_{\text {control }}$ is the absorbance of the negative control (no inhibitor), and $\mathrm{A}_{\text {sample }}$ is the absorbance of each plant extract.

The concentration of each crude extract that inhibited the a-glucosidase activity by $50 \%$ under the assay conditions was defined as $\mathrm{IC}_{50}$ expressed in $\mu \mathrm{g} / \mathrm{mL}$. 
Statistical Data Analysis. The data were analyzed in a complete randomized design with one-way ANOVA using the PROC GLM procedure of SAS 9.4 (SAS Institute, Cary, NC, USA) to compare the means of nutrients and phytochemicals among the different plants and the protozoal cell counts among the different doses of each plant sample. The means of a-glucosidase inhibitory activity were also compared among the different doses within each plant. Orthogonal polynomial contrast was done to determine the linear and/or quadratic effects of plant doses on protozoal cells and $\mathrm{NH}_{3}-\mathrm{N}$ concentration. Significance was declared at $P<0.05$. The GC/MS Translator B.07.17 was used to convert the Chemstat HPLC data files into MassHunter files for qualitative and quantitative analysis of the compounds in the plant extracts.

\section{Conclusion}

The present study demonstrated how new forest plants could be used as potential feed additives for animal husbandry. The tested plants contained bioactive compounds that could suppress the rumen ciliate protozoal population, potentially decreasing the intra-ruminal protein recycling. In addition, the plants were able to inhibit the a-glucosidase enzyme, and thereby potentially mitigating the risk of ruminal acidosis in high-producing cows fed high-concentrate diets. Overall, the leaves of the tested plants contain high levels of protein, especially the leaves of $A$. digitata, K. indica, P. oleracea, and $C$. gigantea, making them new sources of feed for ruminants. However, future studies are needed to evaluate other important nutritional traits, such as digestibility and palatability, and to accurately identify the anti-protozoal phytochemical(s) using the bio-guided fractionation assays.

\section{Abbreviations}

HPLC: High performance liquid chromatography; $\mathrm{NH}_{3}-\mathrm{N}$ : Ammonia nitrogen; NUE: Nitrogen utilization efficiency; VFA: Volatile fatty acid; DM: Dry matter; NDF: Neutral detergent fiber;

ADF: Acid detergent fiber; CAS: Chemical Abstracts Service; TPC: Total phenolic compound;

TFC: Total flavonoid compound; TAC: Total alkaloid compound; GAE: Gallic acid equivalent

RE: Rutin equivalent; AE: Aconitine equivalent; pNPG: p-nitrophenyl-a-D-glucopyranoside;

PBS: Potassium phosphate buffer; GC/MS: Gas chromatography/mass spectrometry

\section{Declarations}

\section{Acknowledgments}

This research was partially supported by the National Key Research and Development Program of China (award number: 2018YFD0501600), the Scientific Research Project for Major Achievements of The Agricultural Science and Technology Innovation Program (ASTIP) (No. CAAS-ZDXT2019004『ASTIPIAS07】 XTCX2016011-01), Beijing Dairy Industry Innovation Team (BAIC06-2020) and International Atomic Energy Agency Technical Co-Operation and Assistance Programme (No. CPR5025). We thank Dr. Mbezele Ngaba Junior Yanick for his contribution in HPLC data analysis.

\section{Author contributions}

A.G.A: Investigation, Formal analysis, writing-original draft, writing-review \& editing. L.M: Methodology, Project administration, X.L \& P.Y: Methodology, J.X, Z.Y \& D.B: Conceptualization, writing-review \& editing. All authors have read and agreed to the published version of the manuscript.

\section{Competing interests}

The authors declare no competing interests

\section{Data availability}

Not applicable

\section{Approval for animal experiments}

All the experimental procedures (protocol number. IAS 20180115) were approved by the Institutional Animal Care and Use Committee at the Institute of Animal Sciences of the Chinese Academy of Agricultural Sciences.

\section{References}

1. Spek, J. W. Variation of milk urea in dairy. A study on factors that affect the relationship between urea concentration in milk and urea excretion in urine. PhD thesis, Wageningen University, 1-162(2013).

2. Newbold, C. J., De La Fuente, G., Belanche, A., Ramos-Morales, E. \& McEwan, N. R. The role of ciliate protozoa in the rumen. Front. Microbiol. 6, 1313 https://doi.org/10.3389/fmicb.2015.01313 (2015).

3. Bacanlı, M. \& Başaran, N. Importance of antibiotic residues in animal food. Food Chem. Toxicol. 125, https://doi.org/10.1016/j.fct.2019.01.033 (2019).

4. Ayemele, G. A. et al. Giant milkweed (Calotropis gigantea): A new plant resource to inhibit protozoa and decrease ammoniagenesis of rumen microbiota in vitro without impairing fermentation. Sci. Total Environ. 743, https://doi.org/10.1016/j.scitotenv.2020.140665 (2020). 
5. Park, T., Meulia, T., Firkins, J. L. \& Yu, Z. Inhibition of the rumen ciliate Entodinium caudatum by antibiotics. Fron. Microbiol. 8, 1189 https://doi.org/10.3389/fmicb.2017.01189 (2017).

6. Krause, K. M. \& Oetzel, G. R. Understanding and preventing subacute ruminal acidosis in dairy herds: A review. Anim. Feed Sci. Technol. 126, 215-236 https://doi.org/10.1016/j.anifeedsci.2005.08.004 (2006).

7. Singh, S. K., Rai, P. K., Jaiswal, D. \& Watal, G. Evidence-based critical evaluation of glycemic potential of Cynodon dactylon. Evid. Based Complement Alternat. Med. 5 (4), 415-420 https://doi.org/10.1093/ecam/nem044 (2008).

8. Wang, Y., Liu, J., Yin, Y., Zhu, W. \& Mao, S. Rumen microbial and fermentation characteristics are affected differently by acarbose addition during two nutritional types of simulated severe subacute ruminal acidosis in vitro. Anaerobe. 47, 39-46 https://doi.org/10.1016/j.anaerobe.2017.04.003 (2017).

9. Braca, A. et al. Phytochemical profile, antioxidant and antidiabetic activities of Adansonia digitata L. (Baobab) from Mali, as a source of health-promoting compounds. Molecules. 23, 3104 https://doi.org/10.3390/molecules23123104 (2018).

10. Abiona, D., Adedapo, Z. \& Suleiman, M. Proximate analysis, phytochemical screening and antimicrobial activity of baobab (Adansonia digitata) leaves. IOSR JAC. 8, 60-65 (2015).

11. Mui, N. T., Ledin, I., Udén, P. \& Van Binh, D. Effect of replacing a rice bran-soya bean concentrate with Jackfruit (Artocarpus heterophyllus) or Flemingia (Flemingia macrophylla) foliage on the performance of growing goats. Livest. Prod. Sci. 72, 253-262 https://doi.org/10.1016/S0301-6226(01)00223-8 (2001).

12. Sun, H., Mu, T., Xi, L., Zhang, M. \& Chen, J. Sweet potato (Ipomoea batatas L.) leaves as nutritional and functional foods. Food chem. 156, $380-389$ https://doi.org/10.1016/j.foodchem.2014.01.079 (2014).

13. Ismail, B. B., Pu, Y., Guo, M., Ma, X. \& Liu, D. LC-MS/QTOF identification of phytochemicals and the effects of solvents on phenolic constituents and antioxidant activity of baobab (Adansonia digitata) fruit pulp. Food chem. 277, 279-288 https://doi.org/10.1016/j.foodchem.2018.10.056 (2019).

14. Olatunde, E., Clement, A., Eduviere, S. \& Owumi, E. Anti-cancer Foods: Flavonoids. Encyclopedia of Food Chemistry. https://doi.org/10.1016/B978-0-08100596-5.21757-5 (2018).

15. Nguyen, M. T. et al. Calosides A-F, Cardenolides from Calotropis gigantea and Their Cytotoxic Activity. J. Nat. Prod. 83, 385-391 https://doi.org/10.1021/acs.jnatprod.9b00875 (2020).

16. Sen, S., Sahu, N. P. \& Mahato, S. B. Flavonol glycosides from Calotropis gigantea. Phytochemistry. 31 (8), 2919-2921 https://doi.org/10.1016/00319422(92)83668-0 (1992).

17. Nadeem, M. et al. Calotropis procera: UHPLC-QTOF-MS/MS based profiling of bioactives, antioxidant and anti-diabetic potential of leaf extracts and an insight into molecular docking. J. Food Meas. Charact. 13, 3206-3220 (2019).

18. Ayele, Y. et al. A methanol extract of Adansonia digitata L. leaves inhibits pro-inflammatory iNOS possibly via the inhibition of NF-kB activation. Biomol. Ther. (Seoul). 21 (2), 146 https://doi.org/10.4062/biomolther.2012.098 (2013).

19. Li, X. N. et al. Profiling hydroxycinnamic acid glycosides, iridoid glycosides, and phenylethanoid glycosides in baobab fruit pulp (Adansonia digitata). Food Res. Int. 99, 755-761 https://doi.org/10.1016/j.foodres.2017.06.025 (2017).

20. Priscila, I. U., Mariama, T. N., da Silva Luiz, C. D. S., Luciano, B. \& Ary, F. J. Antibacterial activity of medicinal plant extracts. Braz. J. Microbiol. 38, 717-719 https://doi.org/10.1590/S1517-83822007000400024 (2007).

21. Belanche, A., de la Fuente, G., Moorby, J. M. \& Newbold, C. J. Bacterial protein degradation by different rumen protozoal groups. J. Anim. Sci. $90,4495-$ 4504 https://doi.org/10.2527/jas.2012-5118 (2012).

22. Belanche, A., de la Fuente, G. \& Newbold, C. J. Effect of progressive inoculation of fauna-free sheep with holotrich protozoa and total-fauna on rumen fermentation, microbial diversity and methane emissions. FEMS Microbiol. Ecol. 362, 1-10 https://doi.org/10.1093/femsec/fiu026 (2015).

23. Ivan, M., Neill, L. \& Entz, T. Ruminal fermentation and duodenal flow following progressive inoculations of fauna-free wethers with major individual species of ciliate protozoa or total fauna. J. Anim. Sci. 78, 750-759 https://doi.org/10.2527/2000.783750x (2000).

24. Park, T. \& Yu, Z. Do Ruminal Ciliates Select Their Preys and Prokaryotic Symbionts? Front. Microbiol. 9, 1710 https://doi.org/10.3389/fmicb.2018.01710 (2018).

25. Ozutsumi, Y., Tajima, K., Takenaka, A. \& Itabashi, H. The effect of protozoa on the composition of rumen bacteria in cattle using $16 \mathrm{~S}$ rRNA gene clone libraries. Biosci. Biotechnol. Biochem. 69 (3), 499-506 https://doi.org/10.1271/bbb.69.499 (2005).

26. Ampapon, T., Phesatcha, K. \& Wanapat, M. Effects of phytonutrients on ruminal fermentation, digestibility, and microorganisms in swamp buffaloes. Animals. 9 (9), 671 https://doi.org/10.3390/ani9090671 (2019).

27. Xue, M. Y., Sun, H. Z., Wu, X. H., Liu, J. X. \& Guan, L. L. Multi-omics reveals that the rumen microbiome and its metabolome together with the host metabolome contribute to individualized dairy cow performance. Microbiome. 8, 1-19 https://doi.org/10.1186/s40168-020-00819-8 (2020).

28. Ivan, M., Dayrell, M., Mahadevan, S. \& Hidiroglou, M. Effects of bentonite on wool growth and nitrogen metabolism in fauna-free and faunated sheep. J. Anim. Sci. 70, 3194-3202 https://doi.org/10.2527/1992.70103194x (1992).

29. Santra, A. \& Karim, S. Nutrient utilization and growth performance of defaunated and faunated lambs maintained on complete diets containing varying proportion of roughage and concentrate. Anim. Feed Sci. Technol., 101, 87-99 https://doi.org/10.1016/S0377-8401(02)00146-3 (2002).

30. Hegarty, R. Reducing rumen methane emissions through elimination of rumen protozoa. Aust. J. Agric. Res., 50, 1321-1328 https://doi.org/10.1071/AR99008 (1999).

31. Park, T., Yang, C. \& Yu, Z. Specific inhibitors of lysozyme and peptidases inhibit the growth of the rumen protozoan Entodinium caudatum without decreasing feed digestion or fermentation in vitro. J. Appl. Microbiol. 127, 670-682 https://doi.org/10.1111/jam.14341 (2019). 
32. Oskoueian, E., Abdullah, N. \& Oskoueian, A. Effects of flavonoids on rumen fermentation activity, methane production, and microbial population. Biomed. Res. Int. https://doi.org/10.1155/2013/349129 (2013).

33. Zeitz, J. O., Meile, L., Michałowski, T., Kreuzer, M. \& Soliva, C. R. Suitability of different media for in vitro cultivation of the ruminal protozoa species Entodinium caudatum, Eudiplodinium maggii, and Epidinium ecaudatum. Eur. J. Protistol. 47, 314-317 https://doi.org/10.1016/j.ejop.2011.04.004 (2011).

34. Vannini, C. et al. Polynucleobacter: symbiotic bacteria in ciliates compensate for a genetic disorder in glycogenolysis. Symbiosis. 44, 85-91 (2007). http://hdl.handle.net/11568/11

35. $\mathrm{Ng}$, F. et al. An adhesin from hydrogen-utilizing rumen methanogen Methanobrevibacter ruminantium M1 binds a broad range of hydrogen-producing microorganisms. Environ. Microbiol. 18, 3010-3021 https://doi.org/10.1111/1462-2920.13155 (2016).

36. Naderer, T. \& McConville, M. J. The Leishmania-macrophage interaction: a metabolic perspective. Cell. Microbiol. 10, 301-308 https://doi.org/10.1111/j.1462-5822.2007.01096.x (2008).

37. Obaroakpo, J. U., Lu, L., Zhang, S., Pang, L. J., Lv, J. \& X. \& a-Glucosidase and ACE dual inhibitory protein hydrolysates and peptide fractions of sprouted quinoa yoghurt beverages inoculated with Lactobacillus casei. Food Chem. 299, 124985 https://doi.org/10.1016/j.foodchem.2019.124985 (2019).

38. Blanch, M., Calsamiglia, S., Devant, M. \& Bach, A. Effects of acarbose on ruminal fermentation, blood metabolites and microbial profile involved in ruminal acidosis in lactating cows fed a high-carbohydrate ration. J. Dairy Res. 77 (1), 123 https://doi.org/10.1017/S0022029909990562 (2010).

39. Mukhopadhyay, P. \& Prajapati, A. K. Quercetin in anti-diabetic research and strategies for improved quercetin bioavailability using polymer-based carriersa review. RSC Adv. 5 (118), 97547-97562 https://doi.org/10.1039/C5RA18896B (2015).

40. Ong, K. C. \& Khoo, H. E. Effects of myricetin on glycemia and glycogen metabolism in diabetic rats. Life Sci. 67 (14), 1695-1705 https://doi.org/10.1016/S0024-3205(00)00758-X (2000).

41. Zhang, B. et al. GAP production of TCM herbs in China. Planta Med. 76, 1948-1955 https://doi.org/10.1055/s-0030-1250527 (2010).

42. AOAC (2000) Official Methods of Analysis. The Association of Official Analytical Chemists, 17th Edition, Gaithersburg, MD, USA. Methods 925.10, 65.17, 974.24, 992.16.

43. Goering, K. \& Van Soest, J. Forage Fibre Analysis (USDA-ARS Agriculture Handbook No. 379, Washington, 1970).

44. Boligon, A. A. et al. Antioxidant activities of flavonol derivatives from the leaves and stem bark of Scutia buxifolia Reiss. Biores. Technol. 100, $6592-6598$ https://doi.org/10.1016/j.biortech.2009.03.091 (2009).

45. Ajanal, M., Gundkalle, M. B. \& Nayak, S. U. Estimation of total alkaloid in Chitrakadivati by UV-Spectrophotometer. Ancient Sci. Life. 31,198 https://doi.org/10.4103/0257-7941.107361 (2012).

46. Chaney, A. L. \& Marbach, E. P. Modified reagents for determination of urea and ammonia. Clin. Chem. 8, 130-132 https://doi.org/10.1093/clinchem/8.2.130 (1962).

47. Rengasamy, K. R., Aderogba, M. A., Amoo, S. O., Stirk, W. A. \& Van Staden, J. Potential antiradical and alpha-glucosidase inhibitors from Ecklonia maxima (Osbeck) Papenfuss. Food chem. 141 (2), 1412-1415 https://doi.org/10.1016/j.foodchem.2013.04.019 (2013).

\section{Tables}

Table 1: Nutritional evaluation and total polyphenols composition of plants leaves.

\begin{tabular}{|c|c|c|c|c|c|c|c|c|c|c|}
\hline \multirow[b]{2}{*}{ Plants species } & \multicolumn{6}{|c|}{ Nutrients content (\%, mean \pm SD) } & \multicolumn{4}{|c|}{ Total polyphenols } \\
\hline & DM & $\mathrm{CP}$ & EE & NDF & ADF & Ash & CEY (\%) & $\operatorname{TPC}(\mu \mathrm{g} / \mathrm{g})$ & $\operatorname{TFC}(\mu \mathrm{g} / \mathrm{g})$ & TA \\
\hline A. digitata & $21.5 \pm 0.1^{\mathrm{e}}$ & $\begin{array}{l}19.8 \pm \\
0.2^{b}\end{array}$ & $1.85 \pm 0.03^{b c}$ & $29.72 \pm 0.93^{c}$ & $24.23 \pm 1.0^{\mathrm{e}}$ & $10.48 \pm 0.2^{\text {de }}$ & $15.1 \pm 0.5^{\mathrm{c}}$ & $5947.0 \pm 0.6^{c}$ & $715.2 \pm 0.6^{c}$ & 41 \\
\hline K. indica & $22.3 \pm 0.2^{\mathrm{g}}$ & $28.5 \pm 0.3^{a}$ & $1.82 \pm 0.2^{c}$ & $53.19 \pm 0.6^{c}$ & $44.96 \pm 0.1^{d}$ & $12.79 \pm 0.3^{b c}$ & $19.1 \pm 0.5^{\mathrm{b}}$ & $2,766.7 \pm 0.6^{e}$ & $580.0 \pm 0.6^{d}$ & 25 \\
\hline C. gigantea & $25.5 \pm 0.1^{f}$ & $\begin{array}{l}17.1 \pm \\
0.2^{c}\end{array}$ & $3.9 \pm 0.1^{\mathrm{a}}$ & $30.73 \pm 2.1^{b}$ & $54.38 \pm 0.6^{c}$ & $16.12 \pm 0.2^{\mathrm{a}}$ & $13.5 \pm 0.5^{c}$ & $3,266.7 \pm 0.6^{d}$ & $1,866.7 \pm 0.6^{a}$ & 44 \\
\hline F. macrophylla & $31.9 \pm 0.1^{d}$ & $10.5 \pm 0.1^{d}$ & $0.9 \pm 0.1^{\mathrm{e}}$ & $48.97 \pm 1.84^{\mathrm{ab}}$ & $34.39 \pm 1.0^{\mathrm{b}}$ & $8.45 \pm 1.4^{f}$ & $9.4 \pm 0.5^{d}$ & $15,466.6 \pm 0.6^{a}$ & $746.7 \pm 0.6^{b}$ & 90 \\
\hline F.macrophylla" & $38.9 \pm 0.2^{b}$ & $7.3 \pm 0.2^{\mathrm{e}}$ & $0.2 \pm 0.1^{f}$ & $53.05 \pm 1.84^{\mathrm{a}}$ & $29.34 \pm 1.0^{\mathrm{a}}$ & $3.28 \pm 0.1^{\mathrm{g}}$ & $13.7 \pm 0.5^{c}$ & $9166 \pm 0.6^{b}$ & $546.7 \pm 0.6^{e}$ & 84 \\
\hline P. oleracea & $32.4 \pm 0.3^{c}$ & $16.6 \pm 0.1^{c}$ & $1.4 \pm 0.1^{d}$ & $59.3 \pm 2.1^{d}$ & $19 \pm 0.68^{f}$ & $9.47 \pm 0.5^{\mathrm{ef}}$ & $8.1 \pm 0.5^{d}$ & $1,413.3 \pm 0.6^{f}$ & $540.0 \pm 0.6^{f}$ & 13 \\
\hline B. rapa c.* & $29.4 \pm 0.1^{a}$ & $10.0 \pm 0.3^{d}$ & $0.4 \pm 0.02^{f}$ & $20.67 \pm 0.8^{c d}$ & $20 \pm 0.83^{f}$ & $11.20 \pm 0.1^{\mathrm{cd}}$ & $40.4 \pm 0.7^{e}$ & $1,106.7 \pm 0.7^{g}$ & $520.8 \pm 0.7^{g}$ & 48 \\
\hline
\end{tabular}

DM : dried matter, CP: crude protein, EE: ether extract, NDF: neutral detergent fiber, ADF: acid detergent fiber, CEY: crude extract yield, TPC: total phenolic compounds,

TFC: total flavonoid compounds, TAC: total alkaloid content.

Different superscripts in the same column denote significant difference $(P<0.05)$. 
\#: only roots were used

*: only tubers were used

Table 2: Phytochemical compounds found in the extract of the forest plants as feed additives for ruminants.

\begin{tabular}{|c|c|c|c|c|c|c|c|c|c|c|c|}
\hline \multirow[t]{2}{*}{ Name } & \multirow[t]{2}{*}{ Formula } & \multirow[t]{2}{*}{ MW } & \multirow{2}{*}{$\begin{array}{l}\text { RT } \\
\text { (min) }\end{array}$} & \multicolumn{7}{|c|}{ Concentration ( $\mu \mathrm{g} / \mathrm{g}$ plant) } & \multirow[b]{2}{*}{ S } \\
\hline & & & & A. digitata & K. indica & $\begin{array}{l}\text { C. } \\
\text { gigantea }\end{array}$ & $\begin{array}{l}F \\
\text { macrophylla }\end{array}$ & $\begin{array}{l}\text { F. } \\
\text { macrophylla"\# }\end{array}$ & P. oleracea & B. rapa & \\
\hline Quercetin & $\mathrm{C}_{16} \mathrm{H}_{10} \mathrm{O}_{7}$ & 302.24 & 15.34 & $157.53^{b}$ & NF & $5,884.29^{a}$ & NF & $101.79^{c}$ & $96.17^{c}$ & $76.39^{d}$ & 3. \\
\hline Anthraquinone & $\mathrm{C}_{14} \mathrm{H}_{8} \mathrm{O}_{2}$ & 208.22 & 21.39 & $82.91^{c}$ & NF & $1,121.77^{a}$ & NF & $100.20^{b}$ & NF & NF & 2. \\
\hline 3-HOBA & $\mathrm{C}_{7} \mathrm{H}_{6} \mathrm{O}_{3}$ & 138.12 & 8.88 & $17,248.73^{b}$ & $40,026.80^{a}$ & $1,020.31^{d}$ & $829.06^{e}$ & $4,514.97^{c}$ & $283.02^{f}$ & $256.99^{g}$ & 3. \\
\hline Astragaloside & $\mathrm{C}_{28} \mathrm{H}_{32} \mathrm{O}_{17}$ & NF & 19.23 & $14,115.36^{a}$ & NF & NF & $11,521.21^{d}$ & $11,580.77^{c}$ & $11,177.09^{\mathrm{e}}$ & $13,427.11^{b}$ & 2. \\
\hline Myricetin & $\mathrm{C}_{21} \mathrm{H}_{20} \mathrm{O}_{12}$ & 464.38 & 11.93 & $4,756.89^{a}$ & $649.00^{\mathrm{b}}$ & $451.31^{\mathrm{C}}$ & $296.40^{d}$ & $237.58^{\mathrm{e}}$ & $98.21^{f}$ & $103.892^{f}$ & 3. \\
\hline
\end{tabular}

MW: Molecular weight, kDa

RT: Retention time in minute

NF: Not found in the plant

\#: Only roots were used

*: only tubers were used

3-HOBA: 3-Hydroxibenzoic acid

SEM: Standard Error Mean

Means with different superscripts within a row differ $(P<0.05)$.

Table 3: Plants effect on rumen ammoniagenesis after $24 \mathrm{~h}$ protozoa culture.

\begin{tabular}{|c|c|c|c|c|c|c|c|c|}
\hline \multirow[b]{2}{*}{ Plant doses $(\mathrm{mg} / \mathrm{mL})$} & \multicolumn{4}{|c|}{$\mathrm{N}-\mathrm{NH}_{3}(\mathrm{mg} / \mathrm{dL})$} & \multirow[t]{2}{*}{ SEM } & \multirow[t]{2}{*}{ Trt } & \multicolumn{2}{|c|}{$P$ value } \\
\hline & 0 & 0.7 & 0.9 & 1.1 & & & Linear & Quadratic \\
\hline A. digitata & 27.4 & 27.0 & 27.4 & 27.7 & 0.8 & 0.990 & 0.941 & 0.778 \\
\hline K.indica & 27.4 & 26.3 & 26.0 & 27.3 & 1.2 & 0.872 & 0.744 & 0.521 \\
\hline C. gigantea & $27.4^{\mathrm{a}}$ & $26.7^{a}$ & $26.5^{\mathrm{a}}$ & $18.5^{\mathrm{b}}$ & 0.8 & 0.004 & 0.006 & 0.007 \\
\hline F. macrophylla & $27.4^{b}$ & $27.0^{\mathrm{b}}$ & $27.2^{\mathrm{b}}$ & $32.2^{\mathrm{a}}$ & 0.6 & 0.021 & 0.053 & 0.013 \\
\hline F.macrophylla" & $27.4^{\mathrm{b}}$ & $27.2^{b}$ & $27.3^{b}$ & $32.6^{a}$ & 0.7 & 0.034 & 0.066 & 0.023 \\
\hline P. oleracea & 27.4 & 27.0 & 27.1 & 27.7 & 1.8 & 0.990 & 0.941 & 0.778 \\
\hline B. rapa chinensis.* & 27.4 & 27.4 & 31.4 & 30.7 & 0.6 & 0.056 & 0.023 & 0.248 \\
\hline
\end{tabular}

SEM: Standard Error Mean

Trt: Treatment

\#: only roots were used

*: only tubers were used

Means with different superscripts within a row differ $(P<0.05)$.

\section{Figures}



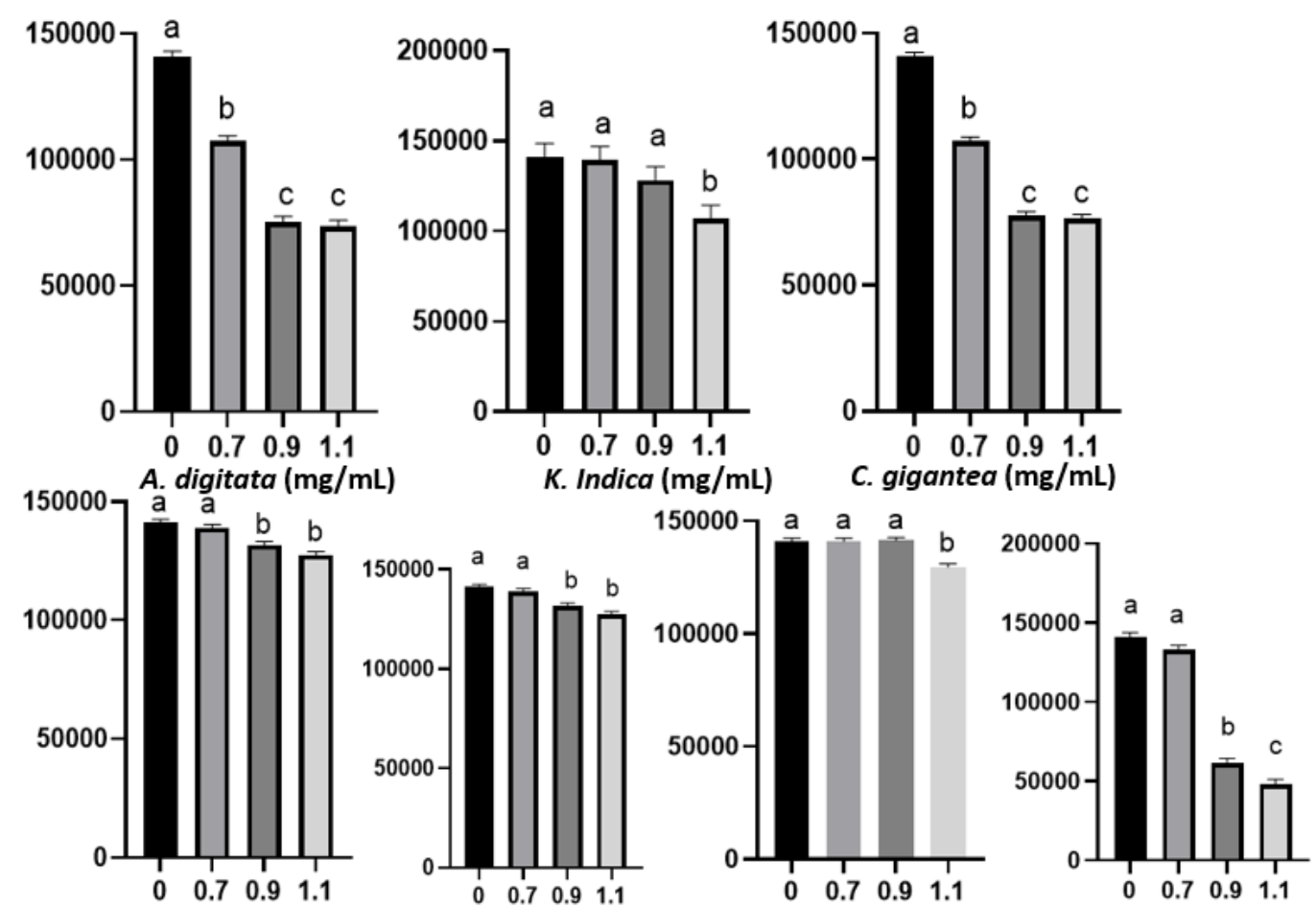

F. macrophylla $(\mathrm{mg} / \mathrm{mL}) \quad$ F. macrophylla $(\mathrm{mg} / \mathrm{mL}) \quad$ P. Oleracea $(\mathrm{mg} / \mathrm{mL})$

\section{B. rapa chinensis $(\mathrm{mg} / \mathrm{mL})$}

Figure 1

Total rumen protozoa counts at different doses of each plant after $24 \mathrm{~h}$ of in vitro incubation. Bars with different lower-case letter differ $(\mathrm{P}<0.05) .{ }^{*}$ Roots were used, \#Tubers were used
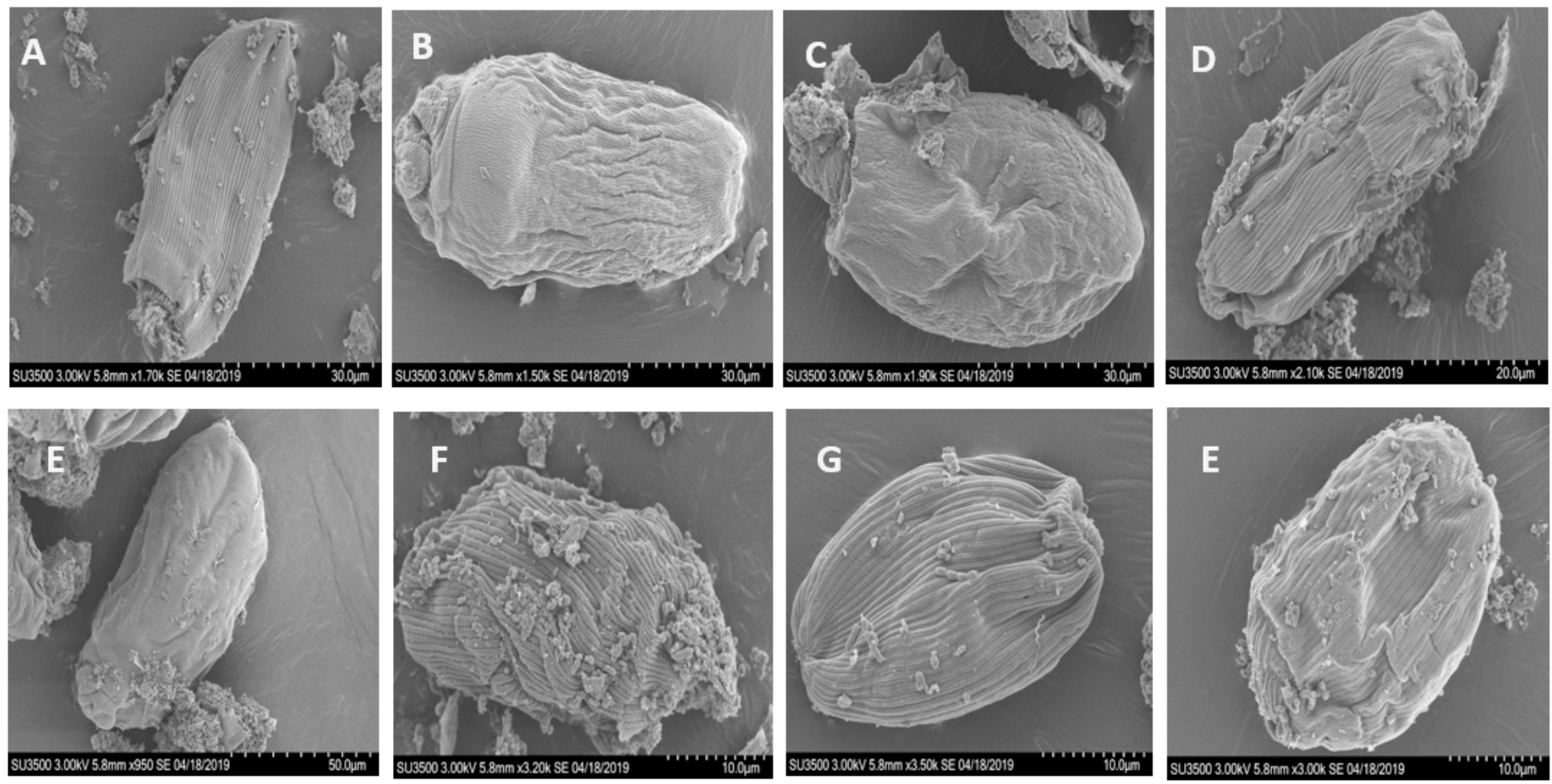

Figure 2

Scanning electron micrographs of Entodinium cells in the in vitro cultures after $24 \mathrm{~h}$ of incubation. A: Control, no plant inclusion, B: Brassica rapa subsp. chinensis, C: Kalimeris indica, D: Calotropis gigantea, E: Adansonia digitata, F: Portulaca oleracea, G: Flemingia macrophylla (roots) H: Flemingia macrophylla (leaves). The cells surface changes were observed at the highest tested dose $(1.1 \mathrm{mg} / \mathrm{mL})$ tested for each plant. No morphological changes to the cell surfaces were observed at the other two lower doses or the negative control (not shown). 

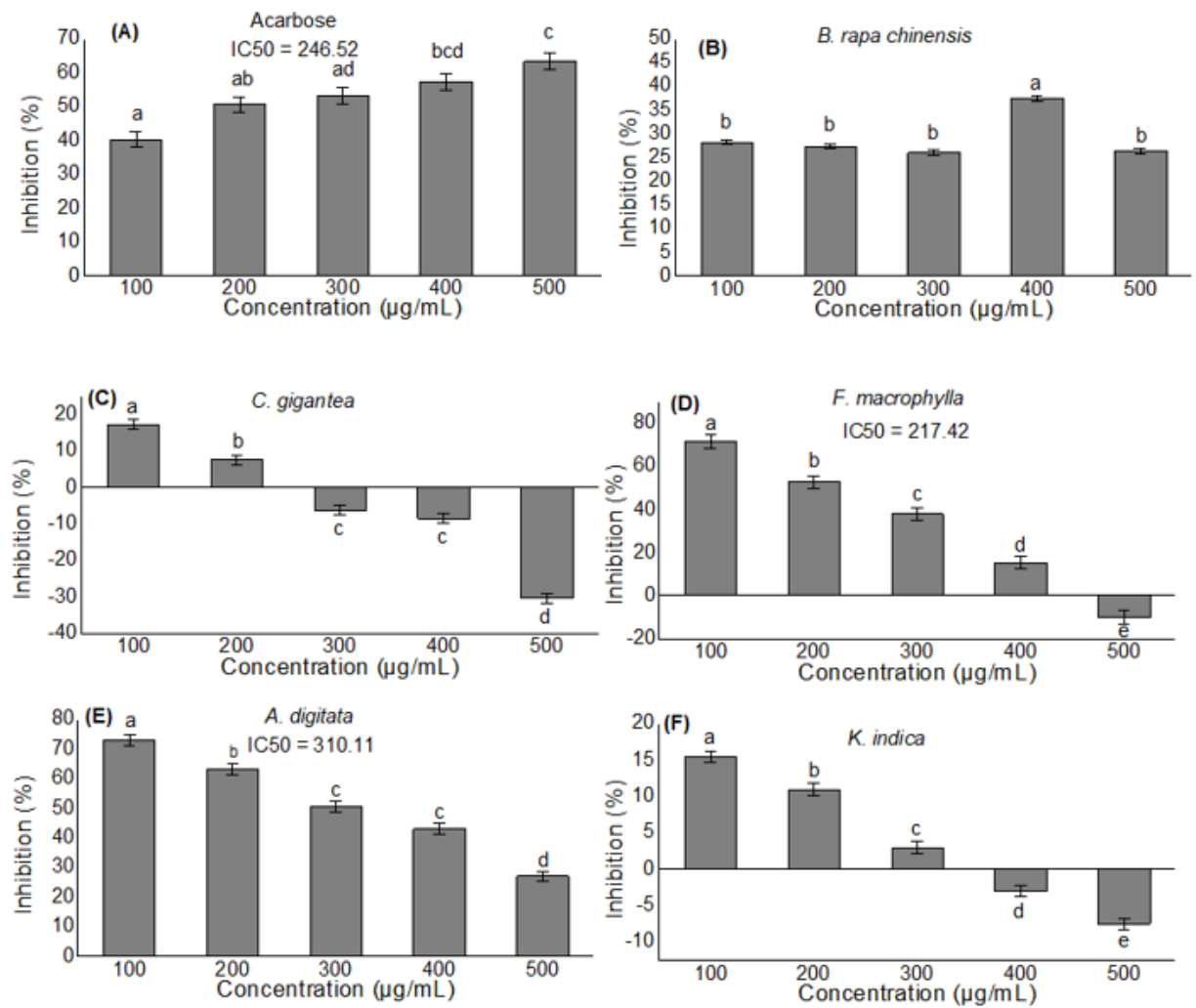

\section{Figure 3}

Inhibition of a-glucosidase activities by the extract of plant leaves and acarbose. The extracts of Portulaca Oleracea and Flemingia macrophylla (roots) samples were missed and we did not test their effect on a-glucosidase activities Means with different lower-case letters on the same graph differ $(P<0.05)$. 